\title{
Editorials
}

\section{Genetic advances in medicine:}

\author{
has the promise been fulfilled in general practice?
}

Since the completion of the Human Genome Project, remarkable advances have been made in understanding the human genome's contribution to health and disease; the wealth of scientific discovery generated over the past 10 years is unparalleled in the history of biomedicine, and the rate of discovery is accelerating. ${ }^{1}$ The traditional study of single gene disorders (genetic medicine) has developed into an understanding of how multiple genes interact with environmental factors: genomics. As these advances were initially greeted with high hopes of early clinical benefit, it is timely to reflect on how much of this promise has filtered through to general practice, particularly in light of The Human Genomics Strategy Group's recent report and policy recommendations about the adoption of genomic technology in the NHS. ${ }^{2}$

\section{CURRENT CLINICAL TESTING}

The majority of genetic tests in the UK are still for single gene disorders. Of most relevance to general practice are the common autosomal recessive conditions for which carrier and neonatal disease screening are offered. The adoption of new tests and testing strategies in the NHS has followed careful consideration of research evidence, much of which occurred in general practice. ${ }^{3}$ With advances in technology, particularly tandem mass spectrometry, the range of conditions included within the neonatal blood spot screening test has expanded lsee NHS screening website http://www.screening.nhs.uk/bloodspotengland).

Antenatal carrier screening for haemoglobinopathies and cystic fibrosis has been successfully integrated into routine clinical care, although achieving informed choice in the former has been shown to be challenging. ${ }^{4}$ Some genetic tests for adultonset conditions already have application in general practice; there is increasing evidence for case finding for familial hypercholesterolaemia, the coagulation disorders including Factor $V$ Leiden, and hereditary haemochromatosis, although uncertainty remains over the utility of population screening for these conditions. ${ }^{5}$

\section{PHARMACOGENETIC AND GENOMIC DEVELOPMENTS}

Pharmacogenetics has frequently been cited as having significant likely benefit to general practice, and internationally these tests are being marketed to GPs. Many studies have demonstrated effects of single nucleotide polymorphisms (SNPs) in metabolic enzymes on commonly prescribed drugs, including different classes of antidepressants, nicotine replacement, and warfarin. CYP2C9 and VKORC1 SNPs are associated with warfarin dosage and risk of bleeding; algorithms exist to calculate warfarin dosage based on genotype, but further evidence is required on cost-effectiveness before implementation. ${ }^{6}$

Cancer genetics provided early exemplars of the 'genetic revolution identifying specific genetic mutations associated with high risk of disease, particularly in breast, ovarian, and colorectal cancer. This led to the development of cancer genetic services in the NHS and guidelines to identify patients most likely to benefit from predictive genetic testing. Identifying more common genetic variants which explain individual variation in risk of heart disease, diabetes, and cancer has proven more challenging. Genomewide association studies have demonstrated associations between SNPs and the presence of many common complex diseases in large patient cohorts. 7,8 However, most SNPs to date only explain a relatively small contribution of inherited risk of disease $(<5-10 \%)$, and there is much still to be done to examine how they interact with common lifestyle factors. ' Despite this, there are several companies offering directto-consumer testing for panels of SNPs, providing individual risk reports for many conditions and suggesting genomicallybased disease prevention advice. The uncertainty about these risk estimates, together with the danger of false reassurance, needs to be balanced against the technological drive as the costs of testing come down. ${ }^{10}$

\section{THE IMPORTANCE OF THE FAMILY MEDICAL HISTORY}

Better DNA-based risk models suitable for use in primary care may still be several years away. In the meantime, the family medical history remains the most relevant genetic risk tool for GPs. The risks of many serious conditions including a number of cancers, ischaemic heart disease, and type2 diabetes are increased in the presence of a family history of the disorder, representing not only shared genetic factors but also environmental and behavioural exposures. This risk increases with younger age at onset and multiple affected relatives. Family history can also be useful to identify people at increased risk of certain conditions due to ethnicity, such as thalassaemia, familial hypercholesterolaemia, and some cancers.

Yet clinicians continue to neglect the family history as part of routine diagnostic assessment and disease prevention. ${ }^{11}$ Not all patients require a full three-generation pedigree which would be considered standard practice in clinical genetics. Simple, self-completed family history screening questionnaires could help to identify those patients requiring a more detailed assessment. No validated questionnaires exist that cover a broad range of conditions relevant to general practice $^{12}$ but they are currently in development. Other barriers to family history taking include uncertainty about the validity of patient reported family history, although recent data suggest that this is over-emphasised, ${ }^{13}$ and concerns about implications for insurance reports. In addition, current general practice-based electronic medical records are not designed to record or update detailed family histories although future iterations are likely to start including suitable tools.

\section{PERSONALISED DISEASE PREVENTION}

The rationale behind genetic risk assessment, particularly for common 
"We are unlikely to be using DNA-based risk assessment in routine general practice until the genomics of common disease is further unravelled ... However, even when this information is available, additional research will be required to translate this into behaviour change and more effective disease prevention."

chronic disease, is to tailor disease prevention advice including disease screening and lifestyle modification. There is some evidence that having knowledge of a family history of a specific condition is associated with improved uptake of a range of disease-preventive activities for breast, colorectal, and skin cancer. But more recent data from people who have received results after purchasing direct-to-consumer DNA tests suggest that it has no impact on uptake of screening tests, diet, exercise, or psychological health. ${ }^{14}$ Therefore, questions remain about the underlying assumption that providing disease risk information will translate simply into healthier behaviours..$^{15}$

While there are some early examples of DNA-based tests which have direct application in general practice, the predicted flood of genetic tests in the first decade of the genomic era has not yet filtered down. Until the genomics of common disease is further unraveled, we will not be using DNA-based risk assessment in routine general practice. Even when this information is available, further work will be required to translate this into effective behaviour change and disease prevention.

We are unlikely to be using DNA-based risk assessment in routine general practice until the genomics of common disease is further unravelled. Given adequate resourcing, future developments could include near-patient tests for specific SNP panels to support pharmacogeneticallyinformed prescribing or tailored cancer screening. Personalised risk assessment tools will integrate genomics data with family history, sociodemographic, behavioural, and environmental risk factors. However, even when this information is available, additional research will be required to translate this into behaviour change and more effective disease prevention.

\section{Fiona M Walter,}

Clinical Lecturer in General Practice, General Practice and Primary Care Research Unit, Institute of Public Health, University of Cambridge, Cambridge, UK.

\section{Jon D Emery,}

Winthrop Professor of General Practice and Head of School, School of Primary, Aboriginal, and Rural Health Care, University of Western Australia.

\section{Provenance}

Commissioned; not externally peer reviewed.

\section{DOI: 10.3399/bjgp12X629955}

\section{ADDRESS FOR CORRESPONDENCE}

\section{Fiona Walter}

General Practice and Primary Care Research Unit, Institute of Public Health, Robinson Way, University of Cambridge, Cambridge, CB2 OSR, UK.

\section{E-mail: fmw22amedschl.cam.ac.uk}

\section{REFERENCES}

1. Feero WG, Guttmacher AE, Collins FS. Genomic medicine - an updated primer. New Engl J Med 2010; 362(21): 2001-2011.

2. Human Genomics Strategy Group. Building on our inheritance: genomic technology in healthcare. London: Department of Health, 2012

3. Emery J, Watson E, Rose P, Andermann A. A systematic review of the literature exploring the role of primary care in genetic services. Fam Pract 1999; 16(4): 426-445.

4. Brown K, Dormandy E, Reid E, et al. Impact on informed choice of offering antenatal sickle cell and thalassaemia screening in primary care: randomized trial. J Med Screen 2011; 18(2) 65-75

5. Qureshi N, Humphries SE, Seed M, et al. Identification and management of familial hypercholesterolaemia: what does it mean to primary care? Br J Gen Pract 2009; 59(567): 773-776.

6. Johnson EG, Horne BD, Carlquist JF, Anderson JL. Genotype-based dosing algorithms for warfarin therapy: data review and recommendations. Mol Diagn Ther 2011; 15(5): 255-264.

7. Relling MV, Altman RB, Goetz MP, Evans WE. Clinical implementation of pharmacogenomics: overcoming genetic exceptionalism. Lancet Oncol 2010; 11(6): 507-509.

8. National Human Genome Research Institute. http://uww.genome.gov/gwastudies/ laccessed 13 Feb 2012)

9. Khoury MJ, Gwinn M, Bowen MS, Dotson WD. Beyond base pairs to bedside: a population perspective on how genomics can improve health. Am J Public Health 2011. [Epub ahead of print].

10. Rafi I, Qureshi N, Lucassen A et al 'Over-thecounter' genetic testing: what does it really mean for primary care? Br J Gen Pract 2009; 59(561): 283-287.

11. Emery JD, Walter FM, Ravine D. Family history: the neglected risk factor in disease prevention. Med J Aust 2010; 192(12): 677-678.

12. Reid GT, Walter FM, Brisbane JM, Emery JD. Family history questionnaires designed for clinical use: a systematic review. Public Health Genomics 2009; 12(2): 73-83.

13. Wilson BJ, Qureshi N, Santaguida P, et al. Systematic review: family history in risk assessment for common diseases. Ann Intern Med 2009; 151(12): 878-885.

14. Bloss CS, Schork NJ, Topol EJ. Effect of directto-consumer genomewide profiling to assess disease risk. New Engl J Med 2011: 364(6): 524-534

15. Claassen $L$ Henneman $L$ Janssens AC, et al. Using family history information to promote healthy lifestyles and prevent diseases; a discussion of the evidence. BMC Public Health 2010; 10: 248 . 